\title{
Política e Estratégia do Desenvolvimento Regional: Planejamento Integrado e Sustentável do Turismo
}

\author{
Mário Carlos Beni ${ }^{\perp}$
}

RESUMO: Apresenta e analisa conceitos que fundamentam a moderna visão do Turismo sobre o Planejamento Integrado e Sustentável do Turismo, que está relacionada à Política e Estratégia do Desenvolvimento Regional. Discute as estratégias de marketing e a competitividade das destinações turísticas, ressaltando o marketstrat e o competstrat.

PALAVRAS-CHAVE: planejamento de turismo, sustentabilidade, turismo sustentável, desenvolvimento regional,política, cstratćgias demarketing,competitividade.

ABSTRACT: This study presents and analyses modern tourism concepts about the integrated and sustainable tourism planning, related to the regional development politics and strategies. It discusses the touristic destinations marketing strategies and its competitiveness poiting out the "marketstrat" and the "competstrat".

KEYWORDS: tourismplanning, sustainability, sustainable tourism, regional development, politics, marketing strategies, competitiveness.

\section{Introdução}

Este artigo trata do tema Planejamento Integrado e Sustentável do Turismo no contexto da Política e Estratégia do Desenvolvimento Regional, visando enfocar conceitos que fundamentam a visão moderna do Turismo.

1. Professor Titular do Departamento de Relaçōes Públicas, Propaganda e Turismo da ECA-USP.

End.: Av. Prof. Lúcio Martins Rodrigues, 443-Bloco B-05508-900-Sảo Paulo-SP.E-mail: beni @ dialdata.com.br 
Nesse sentido apresenta inicialmente consideraçōes gerais, fases, conceitos e definiçōes operacionais no âmbito do planejamento de turismo e do planejamento estratégico e integrado do desenvolvimento sustentável do turismo. Em seguida, destaca a política e o desenvolvimento sustentável do turismo, discutindo a política ambiental, a questão da sustentabilidade, os conceitos de turismo sustentável e de desenvolvimento sustentável do turismo, e a evolução paralela entre o turismo, o desenvolvimento regional e a proteção do ambiente. Por fim discute as estratégias de marketing e a competitividade das destinaçōes turísticas sob nova abordagem que envolve os conceitos de "clusters" e "microclusters", ressaltando o marketstrat (planejamento do marketing estratégico) e o competstrat (política turística de competição estratégica).

\section{Consideraçōes Gerais}

O planejamento de turismo subentende um conceito fundamental: é um sistema inter-relacionado de fatores da oferta e da demanda. Os fatores da demanda são os mercados de turismo internacional e doméstico que utilizam atrativos, equipamentos e serviços turísticos. Os fatores da oferta compreendem atrativos e atividades turísticas, alojamentos e outros equipamentos e serviços. Os atrativos turísticos são os aspectos característicos do local e seus respectivos diferenciais turísticos, e todas as atividades desenvolvidas em função deles. Os fatores da oferta turística, em seu conjunto, podem ser denominados de produto turístico.

Em suma, o processo de planejamento de turismo apresenta as seguintes etapas:

- determinação dos objetivos;

- inventário de todos os recursos turísticos naturais e culturais, com destaque para seus respectivos diferenciais;

- análise e síntese da situação encontrada;

- formulação da política e do plano de turismo, bem como de recomendações de viabilidade;

- implementação e controle de gestão do processo total.

O planejamento de turismo, além de ser um sistema integrado, exige planos a longo prazo e projetos estratégicos.

Os planos a longo prazo referem-se a metas e objetivos específicos e achamse vinculados aos padrōes de desenvolvimento de um futuro determinado. Seu período de duração deve ser de dez a quinze anos, dependendo da previsibilidade dos eventos futuros no país ou na região. Esse período de tempo é necessário para implementar a política e estruturar os planos. Até o desenvolvimento de projetos específicos, tais como grandes "resorts" ou parques nacionais, pode requerer um período de tempo ainda maior.
De outro lado, o planejamento estratégico é um pouco diferente; está mais direcionado à identificação e solução de questões imediatas, com a finalidade de mudar rapidamente situações futuras e enfrentar legal e institucionalmente as transformaçōes necessárias. Orienta-se mais para a ação a curto prazo e para o encaminhamento acelerado de soluções e acontecimentos inesperados.

Alguns estudiosos e pesquisadores de Turismo consideram que o planejamento estratégico, pelo fato de ser mais imediatista, poderá desviar-se do alcance de objetivos de maior prazo, tal como o desenvolvimento sustentável do turismo. Discorda-se dessa posição porque é pela integração da política de longo prazo e do processo de planejamento integrado que o planejamento estratégico surge como o único instrumento apropriado, eis que propicia os meios e métodos de interferência no ambiente ou nas múltiplas dimensões do fenômeno e do fato turístico para reequilibrá-lo, ampliá-lo ou aperfeiçoá-lo. Por último, deve refletir a vontade da população em seu efetivo envolvimento e participação nas atividades de planejamento e desenvolvimento e em sua desejada sustentabilidade.

\section{Fases}

São três as fases do processo de planejamento estratégico e integrado do desenvolvimento sustentável do turismo: estudo preliminar, diagnóstico e prognóstico.

\section{Estudo Preliminar}

- Identificar e descrever a ordenação geopolítica e administrativa da região de estudo.

- Inventariar os recursos ambientais naturais, culturais e artificiais.

- Traçar o perfil socioeconômico da região de estudo.

- Descrever e identificar o estágio em que se encontra o Turismo na região.

- Observar as tendências do tráfego turístico regional, nacional, intra-regional e internacional.

\section{Diagnóstico}

- Analisar os recursos ambientais naturais para a sustentabilidade do Turismo.

- Analisar o patrimônio cultural na região e seu potencial de utilização na sustentabilidade do Turismo.

- Caracterizar e analisar a estrutura social, classificando-a segundo o processo de ocupação territorial, e a medida da participação da comunidade na produção de bens e serviços e nas atividades turísticas. 
- Dimensionar e analisar a estrutura econômica do setor: nível de emprego, volume de investimentos, rentabilidade e consumo.

- Caracterizar e analisar a estrutura político-institucional do Turismo nos setores público e privado.

- Dimensionar e analisar a infra-estrutura regional urbana e de acesso para o processo sustentável de ocupação turístico-recreativa, tendo em vista a abrangência territorial da área de estudo.

- Utilizar indicadores estatísticos e teorométricos para identificar a situação atual e projetar os cenários futuros do comportamento do mercado.

- Caracterizare dimensionar a oferta regional existente e/ou projetada de alojamentos, transportes, equipamentos, instalações e serviços.

- Identificar e caracterizar o diferencial turístico regional para a estruturação das políticas de marketing e de fixação de segmentos do mercado de consumo.

- Caracterizar, classificar e quantificar a demanda atual e futura de bens e serviços turísticos.

- Identificar desequilíbrios entre oferta e demanda do Turismo na região.

\section{Prognóstico}

- Formular políticas e diretrizes de reorientação e programas de ação para assegurar o planejamento estratégico do desenvolvimento sustentável do Turismo na região.

- Estabelecer metas e projetos específicos para garantir a integração da sustentabilidade do desenvolvimento econômico, turístico e social, da área de estudo, observados seus componentes intersetoriais.

- Adotar programas que levem ao desenvolvimento sustentável do produto turístico regional, fatores como eficiência, qualidade e competitividade.

\section{Conceitos e Definições Operacionais}

Política é um curso de ação calculado para alcançar objetivos específicos. Objetivos são direções gerais para o planejamento e gestão do Turismo, e baseiamse em necessidades identificadas dentro de restrições de mercado e de recursos. Políticas são orientações específicas para a gestão permanente do Turismo, abrangendo os inúmeros aspectos operacionais da atividade.

Planejamento é o processo de interferir e programar os fundamentos definidos do Turismo que, conceitualmente, abrange em três pontos essenciais e distintos: estabelecimento de objetivos, definição de cursos de ação e determinação da realimentação, já que a atividade apresenta enorme interdependência e interação de seus componentes.

Planejamento Regional do Turismo é um conjunto de pólos de desenvolvi- mento turístico hierarquizados, unidos por uma infra-estrutura comum, que, em sua totalidade, contribui para dinamizar o desenvolvimento econômico e social de extensas partes do território nacional. O setor de Turismo, que precisa ser sempre expressado e representado em sua complexa totalidade, demanda um tipo de planejamento ao que se agrega a palavra integrado, indicando que todos os seus componentes devem estar devidamente sincronizados e seqüencialmente ajustados, a fim de produzir o alcance das metas e diretrizes da área de atuação de cada um dos componentes a um só tempo, para que o sistema global possa ser implementado e imediatamente passar a ofertar oportunidades de pronto acompanhamento, avali ação e revisão.

O planejamento estratégico estabelece os grandes eixos ou bases do desenvolvimento do Turismo, podendo ser definido como o processo destinado a determinar os objetivos gerais do desenvolvimento, as políticas e as estratégias que nortearão os aspectos referentes aos investimentos, ao uso e ao ordenamento dos recursos utilizáveis para este fim.

\section{Políticae DesenvolvimentoSustentável do Turismo}

Embora o impacto do Turismo sobre o meio ambiente natural e artificial (construído pelo homem) tenha sido reconhecido há muito tempo, a ação demorou bastante para chegar. Parte do problema pode ter sido a falta de conhecimento da relação complexa entre turismo e meio ambiente. Outro fatorfoi a falta de coordenação entre a política de desenvolvimento e a ambiental. Afinal, a questão dos impactos do turismo sobre o meio ambiente começou a ser pesquisada adequadamente a partir dos anos iniciais da década de 1980, quando o turismo expandiu-se rapidamente (Organization for Economic..., 1980). Embora se tenha atingido um razoável progresso, o conhecimento dos complexos processos envolvidos deixou muito a desejar.

As tradicionais divisões de disciplinas retardaram as abordagens multidisciplinares. O caráter multidimensional e os importantes efeitos indiretos envolvidos na inter-relação entre turismo e meio ambiente apenas podem ser entendidos, explicados e operacionalizados através de uma perspectiva sistêmica e holística. Esta permite a identificação dos componentes de ambos os sistemas e sua ação interativa.

A política ambiental também foi fragmentada, dirigida para questões específicas, tais como poluição da água, qualidade do ar e outras. Em parte isso se deve à fragmentação administrativa, mas também ao período de tempo necessário para incorporar abordagens integradas à gestão ambiental, que lida com ecossistemas totais e não com aspectos limitados de qualidade ambiental. Soma-se a esses fatos que a conservação ambiental foi vista comoquestão que estava em oposição à política de desenvolvimento; assim, a qualidade ambiental foi considerada um assunto à parte do desenvolvimento econômico e social. Só recentemente é que prevaleceu a visão mais ampla, mais integrada da política de desenvolvimento, ligando-se esse conceito ao da proteção ambiental. $\mathrm{O}$ aparecimento do conceito de desenvolvimento susten- 
tado (World Commission...,1987) marca essa mudança de perspectiva. A política global de sustentabilidade, em que a conservação do meio ambiente está intimamente relacionada com a eficiência econômica e a justiça social, ganhou ampla aceitação. Essa visão enfatiza esforços para associar a proteção ambiental à s políticas de desenvolvimento do turismo.

Apesar desse apelo conceitual - e político-, a viabilidade da sustentabilidade encontra dificuldades significantes. Como podem ser avaliados os ganhos e perdas sociais, econômicos e ambientais? É a otimização do usodosrecursos compatível com a prosperidade econômica?

Quando é introduzida a questão da escala espacial, surgem importantes conflitos conceituaisè metodológicos. Assim, por exemplo, deveráa sustentabilidade ser buscada apenas no nível global? Poderá ser a sustentabilidade alcançada no nível local ou no regional? (Nijkamp, Van der Bergh e Soeteman, 1990:153-187). Como os ganhos e perdas ambientais, que podem ocorrerem diferentes realidades de espaço, podem ser avaliados?

A questão da sustentabilidade em turismo tornou-se prioritária na Europa, embora muitos dos problemas envolvidos já tivessem sido bastante debatidos no contexto do turismo mundial, principalmente da perspectiva social, cultural e econômica. O Quinto Programa de Ação sobre o Meio Ambiente da União Européia, intitulado Rumo à Sustentabilidade, identificou o turismo como um dos setores prioritários (Commission of the European..., 1993). Na reunião informal do Conselho deMinistrosdo Meio Ambiente, realizadaem Santorini em maiode 1994, o tema central foi Turismo e Meio Ambiente (Ype hode. Ministério do Meio Ambiente..., 1994). No Green Paper on the Role of the Union in the Field of Tourism (1995), o turismo foi considerado como área importante para o incentivo do desenvolvimento sustentável. Apesar do vasto reconhecimento da necessidade de busca de estratégias para o turismo sustentável, parece haver margem muito ampla de interpretações e perspectivas.

O turismo sustentável pode ser interpretado de um ponto de vista setorial, em quea metabásicaé a viabilidade da atividade turística, maisnalinha da sustentabilidade econômica do turismo. Como o foco de interesse é a atividade de turismo, a ênfase de tal estratégia implicará fortalecer, melhorar a qualidade e mesmo encontrar o diferencial do produto turístico, com freqüência na dependência de soluções e inovações organizacionais e tecnológicas. Investimentos na infra-estrutura para aumentar a capacidade emelhorar os serviços, programas de modernização funcional e estética de complexos turísticos, provisão de novas instalações, como salas para congressos, parques aquáticos, etc., são alguns dos instrumentos de política utilizados nesse contexto. Deve-se destacar aqui, com muita ênfase, que todas essas preocupações devem, na verdade, convergir para a oferta de um produto turístico final com atratividade nos mercados regional, nacional e internacional, representada por um processo de comercialização com qualidade e competitividade de tarifas de transporte, alojamento e serviços.

Uma segunda interpretação baseia-se amplamente na ecologia como visão sociocultural e política, acentuando de maneira notável a necessidade de turismo ecologicamente sustentável. Esta é uma abordagem preservacionista em que a prioridade deverá ser dada à proteção dos recursos e ecossistemas naturais.

No contexto da gestão ambiental, algumas atividades de turismo, geralmente identificadas como as do tipo "leve", são aceitáveis como complementares e não perturbadoras ao meio ambiente natural.

A questão pode ser abordada de um ângulo ligeiramente diferente, como desenvolvimento sustentável do turismo, ou a necessidade de assegurar a viabilidade a longo prazo da atividade de turismo, reconhecendo-se a necessidade de proteger certos aspectos do meio ambiente. Esta abordagem, essencialmente baseada numa perspectiva econômica, reconhece que a qualidade ambiental é importante fator de competitividade e, como tal, deverá ser protegida. A proteção estende-se para além daqueles aspectos ou dimensões da qualidade ambiental que estão diretamente envolvidos no desenvolvimento e marketing do produto turístico, o qual deve apresentar sempre mais qualidade e competitividade para um mercado em mudança e expansão contínuas.

Outra abordagem baseia-se no desenvolvimento econômico ecologicamente sustentável, em que o turismo integra a estratégia global do desenvolvimento sustentável e a sustentabilidade é definida com base no sistema total ser humano/ meio ambiente. Desta perspectiva, a conservação ambiental é meta de importância igual à eficiênciaeconômica à justiça social para a geração de empregos, distribuição de renda e melhoria da qualidade de vida.

As políticas de turismo estão integradas nas políticas sociais, econômicas e ambientais, mas não as precedem. Isto constitui a abordagem mais equilibrada e integrada, mais próxima do pensamento contemporâneo sobre o turismo, configurand. e reforçando para os pesquisadores de vanguarda o conceito de "clusters" e microclustersturísticos, delimitados como concentrações geográficas com diferencial interativo e completo, estruturados em sua comercialização global para a concorrência final nos mercados consumidores.

Sempre é válido acentuar que o desenvolvimento sustentável não é objetivo que seja possível atingir a curto prazo, mas é um passo importantíssimo num esforço a longo prazo para salvaguardar o ambiente e a qualidade de vida na comunidade regional e, em última instância, o nosso planeta, conforme Beni (1998).

OTurismoé um elemento importante na vida social e econômica da comunidade regional. Reflete as aspirações legítimas das pessoas no sentido de se desfrutar novos lugares, assimilar culturas diferentes, beneficiar de atividades ou descansar longe do local habitual de residência ou de trabalho. É também importante valor econômico de muitas áreas e cidades e tem contribuição especial na coesão econômica e social das regiões periféricas. O turismo representa bom exemplo da relação fundamental existente entre o desenvolvimento econômico e o ambiente, com todos os benefícios, tensões e conflitos potenciais associados.

Se forem bem planejados e geridos, o turismo, o desenvolvimento regional e a proteção do ambiente podem evoluir paralelamente. Orespeito pela natureza e pelo ambiente, principalmente nas zonas costeiras e de montanha, pode fazer do turismo uma atividade lucrativa e duradoura. 
Além dos investimentos sempre necessários para a otimização da atividade de turismo, o que deve ser feito na prática é a manutenção de um equilíbrio sustentável entre essa atividade e o desenvolvimento e conservação dos valores naturais e culturais, tarefa maior de todos os órgãos e autoridades regionais e locais, não exclusivamente da oferta e demanda de turismo.

\section{Estratégias de Marketing e Competitividade das Destinaçōes Turísticas}

Há tendência dos teóricos progressistas do Turismo de substituírem a expressão "destinação turística" pelo conceito de "cluster", definido como conjunto de atrativos, com destacado diferencial turístico, dotado de equipamentos e serviços de qualidade, com excelência gerencial e concentrado em espaço geográfico delimitado.

Apresenta-se aos distintos mercados consumidores de Turismo como produto acabado, final, com tarifas diferenciadas na forma de "pacotes" em alto nível de competitividade internacional. Assim, um país ou umaregião pode conter um ou mais "clusters" dependendo de sua extensão.

Comefeito, verifica-se com essa moderna abordagem que a concorrência nos mercados regionais, nacionais e internacionais realiza-se entre "clusters", e os produtos turísticos que competem em diferentes níveis nesses mercados são os "clusters" de um país ou região e não os próprios países.

As expectativas dos consumidores turistas e seus correspondentes níveis de satisfação dependem de inúmeros elementos que influirão na percepção final que têm da qualidade de cada "cluster". Esses elementos são: aeroporto, translado, estética do entorno, equipamentos receptivos, gastronomia, hospitalidade da comunidade receptora, informação e sinalização, centros comerciais, serviços de assistência e segurança em geral, todos aliados ao principal motivador das viagens - a competitividade dos preços.

Deve-se observar ainda que cada "cluster" pode, muitas vezes, comporse de microclusters diferenciados que competem em segmentos de mercado distintos

\section{Planejamento do Marketing Estratégico - Marketstrat}

Para cada microcluster de cada "cluster", o planejamento do marketing estratégico visa definir três elementos:

- portfólio de negócios;

- as estratégias de mercado;

- as estratégias de marketing.
Esse planejamento do marketing estratégico deve constituir o programa direcionador do desenvolvimento, tanto para o setor público quanto para o privado, e suas diretrizes devem abranger todos os elementos e áreas envolvidos. Assim tudo deverá integrar, no nível regional (e até dos países compreendidos), um plano geral (marketstrat) que estabeleça o seguinte conteúdo:

- os "clusters" que compõem ou comporão a destinação;

- os mercados e segmentos estratégicos nos quais cada "cluster" deve concentrar seus esforços competitivos;

- as estratégias competitivas e de crescimento de cada "cluster";

- os produtos prioritários a serem desenvolvidos em cada "cluster";

- a ordenação física do território de cada "cluster" e suas etapas ou planos de ação de desenvolvimento;

- modelo de gestão turística do "cluster";

- plano de competitividade de cada "cluster" e seus microclusters.

Se assim for executado, o marketstrat trará os seguintes benefícios:

- para as empresas de turismo: conhecimento detalhado da ação de marketing do setor público e, conseqüentemente, a possibilidade de planejar seus esforços de marketing de forma coordenada com o "cluster" e a região;

- para os "clusters": plano de ação coerente com o planejamento regional e a possibilidade de coordenar suas atividades com as de outros órgãos envolvidos;

- para o governo: guia prático para orientar toda a ação de marketing de forma coerente e rentável;

- para a regiāo: mais benefícios derivados da atividade de turismo sustentável;

\section{Política Turistica de Competição Estratégica - Competstrat}

Definido o planejamento do marketing estratégico, as autoridades devem concentrar seus esforços na criação de um entorno competitivo, o qual deverá constituir a base da política turística. Hoje, o êxito de um "cluster" nos mercados turísticos regionais, nacionais e internacionais depende cada vez menos de suas vantagens comparativas e cada vez mais de suas vantagens competitivas.

As vantagens comparativas baseiam-se na existência de recursos que os competidores não têm, ou os possuem em menor medida: atrativos turísticos únicos, mão-de-obra barata, experiência acumulada e outros. As vantagens competitivas, ao contrário, são criadas. E são criadas levando para o mercado novas formas de competir e novas maneiras de se fazer as coisas. Trata-se, em suma, de processo permanente de inovação que se manifesta no aperfeiçoamento dos produtos, nas mudanças nos processos de prestação de serviços, em novos enfoques de marketing, e assim por diante. 
As vantagens competitivas de um "cluster" são alcançadas pela melhoria e inovação em diversos aspectos, como:

- aumento da qualidade dos recursos e serviços turísticos;

- acrescentar novos e atraentes atributos a esses recursos e serviços;

- melhoria na aplicação de capital.

A empresa de turismo deve aprender a competir em mercados tradicionais cada vez mais sofisticadose a desenvolver sua capacidade decompetirem mercados novos, nos quais os custos dos competidores são altos, mas também é alta a sua produtividade.

O Competstrat trará os seguintes benefícios:

- para o setor privado : a descoberta de uma definição clara de décisão política e um programa preciso e objetivo de apoio a determinados investimentos;

- para outros órgãos públicos em parceria com a iniciativa privada: guia prático para seus empreendimentos e gestão em importantes aspectos, tais como educação, infra-estrutura, urbanismo e outros.

\section{Consideraçōes Finais}

Dada a extrema complexidade do processo global de planejamento que abrange projetos e planos os mais diversos, deve-se sempre visar a unicidade da manifestação do fato turístico, apesar de suas múltiplas expressões. Desde a compra de uma viagem, sua destinação, até o tempo de permanência e regresso à origem, existe a multivariedade de causas e efeitos que o universo do Turismo apenas pode ser compreendido, justificado, explicado e cientificamente tratado por uma abordagem analítica multidisciplinar e sistêmica, estruturada em seus componentes ou subsistemas, conforme exploradoem Beni (1998), eem outras publicações do autor. Todo o exposto teve por finalidade focar, de maneira ampla, determinados conceitos que fundamentam a visãomodernado Turismo que ora se oferece nas dimensões aqui examinadas.

Por derradeiro, quero enfatizar a necessidade de um trabalho cooperativo entre todos os profissionais envolvidos nas artes e nas ciências utilizadas para a exploração e explicação do universo do Turismo, e a parceria que sempre deve ser estabelecida entre governo e organismos representativos da sociedade. E o mais importante para a instrução formal da população, uma vez que o conhecimento da informação tão-somente não é suficiente, é a necessidade da educação consciente para se avaliar e conhecer qualquer campo que desperte a atenção, o interesse profissional e social.

\section{Referências Bibliográficas}

BENI, Mario C. 1998. Anälise estruturul do turismo. São Paulo: SENAC.

COMMISSION OF THE EUROPEAN COMMUNITIES. 1993. Fiff

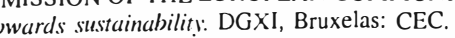

1995. Green paper on the role of the Union in the field of tourism. Bruxelas: CEC

Dimable tourism? Reino Unido: G.K. Priestley.

ORGANIZAÇĀO MUNDIAL DO TURISMO. 1997. National and regional tourism planning-Methodologies and cases. studies. Madrid: OMT.

CIPS, P.A. 1998. Strategic planning slstems in hospitulity and tourism. Reino Unido: Cabi Publishing. ORGANIZATION FOR ECONOMIC COOPERATION AND DEVELOPMENT. 1980. Impacts of tourism on the

NIJKAMP, P., VAN DER BERGH, C.J. e SOETEMAN, F. 1990. Regional sustainable development and natural resource use. In: PROCEEDINGS OF THE WORLD BANK ANNUAL CONFERENCE ON DEVELOPMENT ECONOMICS. Washington: IRBD/World Bank

WORLD COMMISSION ON ENVIRONMENT AND DEVELOPMENT. 1987. Our commom future. Oxford: Oxford University Press. 267p

PEHODE (Ministério do Meio Ambiente, Planejamento e Obras). 1994. Informal council of ministers of the environment of the European Union. Atenas.

Recebido em 2/3/99

Aprovado em 26/4/99 